\title{
Sistema de Nominação, Pertença, Medos e Controle Social. 0 Uso dos Apelidos entre um Grupo de Jovens da Cidade de João Pessoa, Paraíba.
}

Mauro Guilherme Pinheiro Koury $U F P B$
Este artigo busca discutir o uso dos apelidos entre um grupo de jovens da cidade de João Pessoa, Paraíba, aqui denominado Delta ${ }^{1}$. O uso de apelidos para se autodenominarem foi o que primeiro chamou a atenção do autor quando da aproximação inicial com o grupo. Este estranhamento, comum na pesquisa antropológica quando o pesquisador começa a tomar contato com o outro como objeto de estudo, foi motivado pelo fato de os apelidos evocarem características individuais dos sujeitos que os recebem não de todo elogiáveis. Ao contrário, na maioria das vezes o apelido exprime uma faceta que normalmente era e é considerada vergonhosa pelos indivíduos que a possuíam. Uma segunda característica à qual se atentou durante os primeiros contatos em campo foi o fato de os apelidos serem assumidos pelos portadores como quase nomes próprios, muitas vezes se auto-referindo pela própria alcunha.

Não se usa o nome com que eles se autodesignam, neste trabalho, a pedido dos membros do próprio movimento, para evitar possíveis embaraços para com o grupo ou seus membros. O nome fictício Delta foi escolhido pelo autor, que o submeteu e que foi aprovado pelo grupo. A palavra Delta foi eleita por designar a letra grega delta e por representar o sentido de margens que confluem, como um delta de um rio, por exemplo, explicitando os propósitos do grupo enquanto unidade e projeção de si mesmo nos membros e da visão dos membros sobre os sentidos do grupo.

Os diversos sentimentos expressos pelo termo Delta possuem uma relação, assim, em parte, com o verdadeiro nome do grupo. O nome atribuído tem correspondência, também, com os objetivos mais abstratos do movimento, 
da aceitação da palavra e do sentido grupo como fundação societária e às mudanças para cada um que os admite.

É importante observar, contudo, que a nominação do grupo representa um ato de presença do movimento em cada um dos que dele fazem parte, diferenciando-os dos demais existentes fora do grupo. A existência de um nome, entre os Deltas, deste modo, é fundamental para a compreensão analítica do próprio movimento. O reconhecimento através do nome, ou da denominação de si próprios como membros, parece construir e ampliar o sentimento de companheirismo e de pertença ao grupo e permitir ao movimento em sua totalidade e a cada membro singular situar-se em um lugar de fala e de atribuição desde onde interage entre iguais ou com os de fora. Pertencer ou sentir-se pertencendo é fazer parte do movimento, isto é, é ser um Delta.

\section{QUEM SÃO OS DELTAS?}

O grupo Delta é autocaracterizado como uma comunidade de apoio e afirmação aos jovens de bairros populares da cidade de João Pessoa, estado da Paraíba. O movimento atua, principalmente, em bairros situados próximo ao centro da cidade de João Pessoa, embora afirmem possuir, em número menor, membros distribuídos por outros bairros populares da capital. É formado por jovens de ambos os sexos de uma faixa etária dos 15 aos 30 anos de idade. Uns poucos membros, é bem verdade, chegam a ter uma idade mais elevada do que trinta e, embora não deixem a militância, passam a ter uma presença mais simbólica do que efetiva no grupo, servindo como consultores ou conselheiros para problemas internos ou externos do movimento, ou como memória social e em relação aos princípios e ideário Delta.

São jovens com uma história de vida difícil e uma presença no mundo conturbada seja por questões ligadas a problemas econômicos ou familiares, seja por problemáticas de fundo social, afetivo ou emocional, até a entrada no movimento. Esse corte na vida de cada membro entre o antes e o depois de pertencer ao Delta é fundamental para a caracterização do significado da presença do grupo na vida de cada um e do próprio sentido simbólico atribuído ao grupo em sua totalidade pelos que dele fazem parte.

A mudança na qualidade e estilo de vida após a adesão ao grupo Delta perfaz, deste modo, uma espécie de renascimento para o mundo social e psicológico de cada membro. Este fato, inclusive, é fundamental para compreensão da cultura política Delta enquanto construção simbólica de inclusão social dos seus membros e vinculação interna entre eles e entre cada membro em relação ao grupo. 
O renascimento para o mundo, realizado no processo de adesão, configura-se como uma espécie de batismo onde cada novo membro opta por um novo nome com que passa a se designar e ser designado no interior Delta. Todos os membros do grupo possuem uma espécie de cognome, um apelido que, normalmente, diz respeito a uma característica física ou de personalidade do sujeito apelidado. $O$ apelido parece assumir uma espécie de marca registrada de individualidade e de aceitabilidade, um sinal pessoal distintivo e de reconhecimento individual no grupo.

Este novo nome remete o sujeito que adere a conviver com o seu passado em forma de um autoapelido, como forma de rememoração contínua do que foi e o "novo ser" que surge com a entrada no movimento. Novo ser, revivido, inclusive, como uma espécie de ritual de comunhão, em cada encontro Delta, como uma forma de reviver e reconfigurar a fé e a confiança no grupo como um todo, em cada membro, e na relação de igualdade predisposta entre os diversos membros em relação.

O novo membro que nasce após a entrada no movimento ressurge também para o social mais amplo como um ser mais integrado ou que busca um melhor papel na sociedade em torno e, em termos psicológicos, mais ajustado e confiante em si mesmo pela assunção da palavra, ou do sentido Delta, em si. Deste modo, são jovens que normalmente retornam à escola, muitos hoje já estudantes de terceiro grau ou já formados e atuantes em diversas profissões, que voltam a ter um melhor relacionamento com a família, com os amigos, maridos e esposas, com os companheiros, com os filhos, e consigo mesmo, e que detêm uma acepção de mundo enquanto direção, sentimento de adesão, de missão ou conquista. São jovens que procuram sair de si enquanto problemática existencial e que abrem para si um processo de atuação que vai da busca de conquistar um espaço social até o esforço de ampliação da rede Delta entre os jovens de fora do movimento, tendo sempre o processo do que foi, antes da adesão, como o sentido e a força de sua construção social, enquanto membro singular e enquanto coletividade.

É o esforço de constituição de um movimento afirmativo e de apoio que interessa analisar neste artigo e suas conseqüências para a ação e a construção social. As tensões resultantes, os impasses entre as ações individuais e coletivas decorrentes, o significado e a vivência prática do pertencer ao movimento, em cada membro e no grupo em geral, o significado da adesão na vida de cada um e as conseqüências desta adesão nas relações com os demais membros e os de fora do grupo organizam a problemática deste artigo.

As hipóteses trabalhadas também perpassam as questões sobre o ideal de ser um Delta e o medo de não o conseguir, vivido internamente por cada membro e nas práticas relacionais grupal, assim como o ver a si mesmo, os outros membros e os de fora. A lógica e o uso e os sentidos dos termos confiança e lealdade na vida de cada membro e nas relações grupais, enfim, situam as diretrizes deste artigo, em sua busca de compreensão do sistema de nominação do movimento aqui chamado de Delta. 


\section{O SISTEMA DE NOMINAÇÃO ENTRE OS DELTAS}

Entre os Deltas, todos os membros possuem uma espécie de cognome, um apelido que, normalmente, diz respeito a uma característica física ou de personalidade do sujeito apelidado. Por exemplo, Porcão é o apelido de um rapaz do grupo, gordo e de aparência suada e com muitas espinhas no rosto, membro dos Deltas. Em várias conversas a sós com o pesquisador ou em grupo, com outros membros, o informante muitas vezes referiu-se a si próprio pelo apelido. $\mathrm{O}$ apelido parece assumir para ele, e por extensão para todos os membros do grupo Delta, uma espécie de marca registrada de sua individualidade e de sua aceitabilidade no grupo, associando o cognome dado a cada um a uma espécie de marca pessoal distintiva de reconhecimento individual $^{3}$ e de medição do esforço pessoal para vencer barreiras e aperfeiçoar-se constantemente no grupo.

A naturalização dos defeitos ou diferenças físicas ou de personalidade através dos apelidos, parece fazer cada membro do grupo pensar a sua diferença, recortada e evidenciada pelo cognome, como individualidade e reconhecimento individual junto aos outros membros. Em certo sentido pode-se fazer uma referência ao artigo de Mauss (1974) sobre as técnicas corporais, onde o sistema de nomenclatura entre os Deltas teria uma função técnica de re-socialização e de controle social através da inibição pela acerbação dos medos e receios decorrentes dos defeitos pessoais por eles considerados, adestrando os membros e o conjunto do grupo a repersonalizarem-se aceitando e percebendo as diferenças de cada um como uma nova postura no e para o mundo. $\mathrm{O}$ que levantou uma série de considerações ao pesquisador sobre a relação dos apelidos à situação de pertença e do controle social resultante entre os Deltas.

Qual o significado do uso de apelidos no grupo? Porque os apelidos dados e aceitos por cada membro são sempre calcados em aspectos aparentemente depreciativos, no social mais amplo, àqueles que os possuem? O que tem isso a ver com a questão do controle social entre os Deltas? Por que estimulam o sentimento de pertença ao grupo e não o seu contrário, como seria de esperar quando alguém é chamado por uma alcunha que não necessariamente envolva aspectos positivos da personalidade ou características físicas dos sujeitos que as possuem? Como um apelido que busca tornar visível algum aspecto que normalmente um indivíduo gostaria de ter escondido ou pelo menos não notado, pode ser sentido pelos que os usam como uma baliza para a individualidade e consideração pessoal? Que tipos de interação acontecem no interior do grupo a partir desse sistema de nominação?

Apelidos, cognomes, alcunhas ou epítetos são termos que têm origem na palavra grega epitheyon, que significa, segundo Machado (2001), o adjetivo ou vocábulo que articulado a um nome provoca uma designação característica e particular. Aplica-se, deste modo, a uma pessoa ou coisa para indicar uma particularidade ou qualidade. 
Para o Dicionário Aurélio de Língua Portuguesa, o termo apelido denota uma designação especial a alguém ou a alguma coisa, embora em uma formulação transitiva direta e indireta possa ter o sentido de convite ou convocação. Apelidar possui, deste modo, a acepção de designação, denominação, cognonimação, bem como de convocar ou convidar. Do mesmo modo, ainda segundo o Aurélio, o termo apelidar tem o significado de pôr alcunha ou apelido em alguém, alcunhar, podendo ainda ter o sentido de sobrenome de família.

Ao se verificar os sentidos atribuídos ao termo alcunha, por sua vez, ainda seguindo o Dicionário da Língua Portuguesa de Aurélio Buarque de Holanda, os mesmos indicam a denominação acrescentada ao nome propriamente dito de uma pessoa, ou usado para substituí-lo, denotativo seja de particularidades referentes a seu ofício, seja de um traço característico de sua pessoa ou vida. O que, por sua vez, pode ser um apelido que se põe em alguém e pelo qual passa a ser conhecido, bem como um epíteto depreciativo derivado de qualquer particularidade física ou moral. Do mesmo modo, para Machado (2001), uma alcunha é uma figura de estilo que pode ser usada com o sentido de um impropério e ter um caráter ofensivo, embora não seja essa a regra, sendo também usada para designar qualidades do sujeito que o usa ou é por ele designado.

Segundo a Enciclopédia Wikipedia (2003), o termo alcunha pode estar relacionado a várias situações do sujeito a quem é atribuído. Pode estar referenciado diretamente ao primeiro nome da pessoa ou ao seu sobrenome, ou pode indicar o seu trabalho ou profissão. Pode ressaltar, também, a nacionalidade ou lugar de origem da pessoa alcunhada, com sentido ofensivo ou não, ou pode ter o sentido irônico e maldoso de sublinhar características físicas ou morais dos sujeitos nomeados, de forma direta ou por oposição como, por exemplo, avocar um indivíduo de gordo, realçando a sua característica física, ou chamá-lo de magrão, ressaltando a sua gordura pela aposição irônica do seu contrário.

A alcunha pode ainda estar relacionada a uma característica do caráter da pessoa, ou apontar um incidente ou ação específica do sujeito alcunhado, ou pode também ter um caráter ficcional de origem não necessariamente clara e direta.

Pela direção etimológica apresentada acima é possível pressupor então que, apesar dos termos apelido e alcunha serem tratados como sinônimos, um tendo implicação sobre o outro, os dois, ao mesmo tempo, indicam uma série de particularidades que remetem a uma especificação diferenciada de cada termo. Neste sentido, o termo alcunha parece ser um subproduto de apelido, denotativo de particularidades impostas por uma denominação ao nome ou à pessoa que o possui, adjetivando-a positiva ou negativamente. Já o termo apelido tem o sentido mais amplo, não só de um cognome adjetivado, mas de um sobrenome, no qual a pessoa que o leva ou a quem ele é atribuído o recebe como uma espécie de atribuição especial, assumindo- 
o como um tipo de convite ou convocação para pertencer a uma comunidade, a uma articulação relacional específica, a um grupo, ou a uma espécie de organização social determinada.

O termo apelidar, assim, invoca o sentido de pertença a um grupo, diferente do de alcunha, que parece indicar um denotativo mais individualizado a quem o possui ou para quem é dirigido, não importando aqui se no sentido positivo ou negativo. Alcunhar é, deste modo, a individualização de uma ação sobre uma pessoa e referencia uma marca pessoal distintiva, seja de fundo moral seja de contento físico. Pode, portanto, ser tanto inclusiva, aí no sentido mais social e próximo ao significado do termo apelidar, como exclusiva e individualizante. Servindo, no último caso, para simbolizar aspectos físicos ou morais positivos do indivíduo a quem é atribuído - por exemplo, fulano, o bom - e negativos - sicrano, o vesgo. Ambos os aspectos ressaltando características individuais mais próximas ao que Goffman (1988) chama de estigma.

A distinção sutil neste trabalho é mais metodológica do que real, entre os termos apelido e alcunha, já que os dois estão relacionados nas possíveis significações do nomear indivíduos e coisas na vida social cotidiana. É necessária, contudo, para entender os movimentos simultâneos e em muitos sentidos relacionais um a outro do uso de epítetos como parte de um sistema de nominação entre os Deltas.

Todo Delta é conhecido no interior do grupo por uma espécie de alcunha individualizante, na maior parte das vezes aplicada a partir de uma característica, mormente ligada a um aspecto socialmente ${ }^{4}$ considerado ofensivo à pessoa que o carrega ou o detém. Este aspecto individualizante, assim, é carregado do sentido estigmatizante que ironiza ou ridiculariza a pessoa que o carrega, e que faz o mesmo sentir vergonha ou sentir-se ofendido ou em crise de ansiedade quando deste modo abordado. Ao mesmo tempo, por outro lado, este aspecto individualizante, pelo sentido ofensivo socialmente, no interior do discurso Delta é visto e sentido pelos seus membros como um elemento integrativo e de suporte pessoal de cada Delta na relação com um outro do grupo, e como pessoa para fora do grupo.

Esta contradição aparente remete, conseqüentemente, para o sentido atribuído pelo grupo à alcunha como uma espécie de sobrenome grupal. Como uma espécie, portanto, de apelido, na sua acepção mais integradora de enraizamento a uma prática cultural específica.

O que transforma o sentido individualizante da alcunha em apelido, isto é, como uma espécie de convite à integração de cada membro ao grupo. Um sentimento de pertença a cada um dos membros parece ser assim atestado, aqui usando como uma espécie de fundamento compreensivo a noção meadmiana do 'mim' $(\text { Mead } 1934)^{5}$, enquanto problema da interpessoalidade que coloca o sujeito no mundo em sua relação com o outro, ou com o objeto da sua relação, tornando-o pessoa pelo uso do apelido. Apelido entendido com o caráter não mais de alcunha ou epíteto, pejorativo ou não, mas como uma espécie de metalinguagem pela 
qual se organiza e dirige - cada um e a totalidade grupal - o embate interno de cada membro consigo mesmo e com os outros do grupo e o estabelecimento de relações com o mundo em geral (Koury 2001).

O sistema de nominação Delta, através da atribuição de apelidos, ao agir como metalinguagem estimulando o sentimento de pertença e o enraizamento de cada membro ao grupo, parece provocar entre cada um dos membros uma atitude de autocompreensão e respectivamente de conquista e inserção no mundo Delta e fora dele. Como uma espécie de antes e depois da entrada na comunidade, parece gerar uma ação simultânea de assunção de um lugar por onde cada qual se enxerga e se insere na comunidade Delta e, a partir daí, no mundo social em geral.

Atribuir um apelido parece ter no grupo um significado parecido com o empregado por Mauss ao tratar dos potlatch de destruição, onde o "dar já é destruir" (1974:100). A atribuição de um novo nome, acerbando as características distintivas físicas ou de personalidade de um novo membro, tem a propriedade técnica de destruição dos defeitos aparentemente existentes e, de forma simultânea, o movimento novo de re-socialização e individuação. Técnica onde a dádiva da atribuição aprofunda a relação entre troca e contrato, que se transfiguram em um revigoramento da individualidade pessoal de cada novo membro para o mundo social geral e em uma revitalização do controle social Delta sobre seus membros e para si próprio enquanto movimento coletivo.

\section{RITUAL DELTA DE NOMINAÇÃO}

Como é possível e como se dá à passagem da atribuição de alcunha em apelido, isto é, do processo individualizante para o processo de integração à coletividade entre os Deltas? Essa questão se colocou durante o decorrer de todo o trabalho de campo com o grupo, mas que só aos poucos foi ganhando sentido como uma espécie de quebra-cabeça cujas peças iam se encaixando cada vez que o pesquisador adentrava na intimidade do coletivo, e que cada entrevistado permitia discutir os significados da atribuição dos nomes com os quais passariam a ser reconhecidos pela comunidade, como também reconheceriam a si próprios.

Todo Mundo é o epíteto atribuído a uma jovem Delta e por ela incorporado como seu nome pessoal para o grupo. “É através dele que eu consigo me ver melhor como uma pessoa que quer melhorar e aprimorar o meu sentimento e as minhas relações com os outros, sejam eles meus irmãos por afinidade ou qualquer um que seja", disse ela na segunda entrevista ${ }^{6}$ formal e após vários encontros informais com o pesquisador, sozinha ou em grupo. 
Todo Mundo é uma moça de 23 anos, tem o segundo grau completo e trabalha como digitadora em uma distribuidora de medicamentos no centro da cidade de João Pessoa. Desde os 16 anos, segundo ela, passou "de mão em mão por vários namorados ou caras que eu encontrava em festinhas, pela praia, ou mesmo na rua e por onde que eu fosse. Eu era uma menina que andava com todo mundo e era falada e não conseguia manter amizade ou relacionamento sério com ninguém. Morria de vergonha quando via alguém me apontando por perto da rua que eu moro, e morria de culpa pelos meus pais e meus irmãos que não tinham nada com isso e se aperreavam com as coisas que diziam de mim por todos os lados, e mesmo pelas atitudes que eu proporcionava na minha gritaria em casa, ou mesmo na rua, para dizer que ninguém tinha nada a ver com minha vida".

Todo Mundo não parava em emprego, deixou de estudar e completou o segundo grau depois através do supletivo. Vivia, segundo ela, em brigas constantes com o mundo, com a família e com ela própria, na ambivalência da vergonha e culpa, e da busca de independência na afirmação do "ninguém tinha nada a ver com minha vida".

Aos dezenove anos entrou em contato pela primeira vez com o grupo Delta de forma acidental. Estava em uma festinha e deu "em cima de um cara, chamei ele pra sair comigo e ele me esnobou. Fiquei puta da vida, na maior raiva voltei pra casa querendo chorar e segurando as lágrimas. Dois dias depois estava tomando um lanche no intervalo do trabalho e vejo ele do outro lado do balcão. Finjo que não vi e vou comendo o mais rápido que possa para sair daquele local. Ele me vê e se aproxima, fala comigo e eu não respondo, mas acho que fiquei feito um camarão de vermelha, pelo menos me imagino assim. Ele não arreda o pé e eu termino trocando algumas palavras com ele...

“Depois de dois meses a gente está já se encontrando regularmente e ele, embora muito agradável, não tinha jeito de dar em cima de mim e parecia que não entendia as tiradas que eu jogava pra ele. Até que uma vez eu ataquei ele assim, de vez, sem que ele tivesse tempo de fugir ou se esquivar e ele me segurou e me puxou pra uma mesa, pediu dois guaranás e olhou pra mim e perguntou porque eu era assim. Foi um choque que tomei, quis me levantar mas ele não deixou e, pela primeira vez, conversei com alguém sobre mim mesma e fui ouvida sem recriminação e fui, a partir daí, me aproximando da turma dele, rapazes e moças, que passaram a ser minha turma, e fui me achegando, me achegando e quando me vi estava Delta".

Ao perguntar se a alcunha de Todo Mundo tinha sido a ela atribuída antes de se tornar Delta ela diz que não e informa que o cognome foi dado numa das muitas rodadas de conversa com os novos amigos. Conversas onde cada qual "falava um pouco de si mesmo e era instigado a dizer um nome, que podia ser qualquer um, com que melhor dizia ou definiria a vida de cada um até o momento da entrada no grupo". Quando a pessoa 
não sabia se expressar ou usava um termo que os outros não aprovavam, começava "uma rodada de nomes até que um era aceito pela pessoa e atribuído a ela como seu, e daí em diante as pessoas começavam a chamar por aquele apelido e a gente mesmo a se chamar, porque se reconhecia nele, pelo que fora até então e no que não queria mais ser, passando a então buscar uma melhora pessoal".

A narrativa de Todo Mundo, em certo sentido, guardando as particularidades da história pessoal de cada um e daquilo que, até a chegada ao grupo, era motivo de chacota pelos outros ou de vergonha ou estranhamento pessoal, era muito parecida as demais. Todas narram a atribuição de uma alcunha vista e sentida como um apelido, como uma espécie de batismo ou imersão no grupo. Assim, por exemplo, Tiquito é o apelido de um rapaz do grupo, miúdo, de aparência doentia e parecendo muito tímido. Como todos, refere-se a si próprio pelo apelido, e informa, em sua entrevista ${ }^{7}$, que o termo Tiquito foi dado por ele mesmo, numa das muitas "rodadas de conversa" com o conjunto dos membros do Delta.

Galinha d'Água, por sua vez, é uma moça que tem uma um tom de voz estridente, como um cacarejar, e que quase não saía de casa e não falava com ninguém, com vergonha de sua voz, até conhecer e pertencer ao Delta. Diz, em uma das conversas com o pesquisador ${ }^{8}$, que, "numa rodada de conversa, todo mundo começou de repente a falar de seus apelidos, de contar o que eram antes da entrada no grupo e coisa assim e, de repente, me perguntaram como eu me chamaria se eu tivesse que resumir tudo o que eu tinha vivido até aquele momento e que me fazia mal. Confesso que fiquei sem jeito, envergonhada mesmo, pensando que iriam aproveitar para esculhambar de mim, mas como todo mundo parecia não prestar atenção ao meu malestar e continuava falando e rindo de tudo e de todos, fui me libertando e cheguei a dizer que era a minha voz que parecia um cacarejo. Que eu me chamaria de Cacarejo. Aí a turma disse tá certo, mas e se fosse isso, e se fosse aquilo, até que um lançou galinha d'água, um pássaro, segundo ele, que ficava se debatendo na água e zoando com uma voz de taquara rachada. Aí eu disse: gostei desse, e fiquei sendo a Galinha d'Água".

Colchão é o apelido de um rapaz gordo de barriga e peitoral flácidos. Cabelinho, um rapaz com menos de vinte anos e possuidor de uma grande calvície. Mingau, um rapaz muito branco, "como um mingau" (leite engrossado com maisena, ou similar) e com aspecto de mimado "criado com vó". Arremesso, por não ter "papas na língua", e viver como que quase arremessando palavras e gestos. Cleidita, apelido de uma moça que parece querer "se passar por menininha"; Popô, apelido de um rapaz que "tem bunda grande e gorda"; Bolinha é uma moça gordinha e metida a engraçada; o apelido de Pensão, por sua vez, vem "de eu ser metido a parecer um pensador, um cara maior do que os outros", entre muitos outros. Todos os apelidos revelam um aspecto do indivíduo, que se atribui ou que foi atribuído pela alcunha, que referencia o passado. Busca expressar aquilo que melhor sintetizaria o que cada um foi antes de ingressar no grupo Delta. 
O apelido, assim, parece servir como um desafio pessoal para reconhecimento da memória do 'eu' antes da entrada no grupo, e para significar aquilo que não mais quer ser. É revelador, desse modo, de uma possibilidade nova de inserção no mundo como melhora de si e dos outros. $O$ apelido assume, desse jeito, uma espécie de marca registrada de individualidade e de aceitabilidade de cada membro no grupo. O cognome dado a cada um é associado a uma espécie de sinal pessoal distintivo e de reconhecimento individual na coletividade e entre cada um dos seus interlocutores no espaço grupal, o que o torna uma espécie de sobrenome pessoal no coletivo.

A alcunha ou epíteto, ao individualizar o sujeito, qualificando-o na medida exata do que tem de mais difícil de ser encarado em cada um na rememoração de sua curva de vida, torna-se, quando atribuído nas "rodadas de conversa" sistemáticas entre os Deltas, uma espécie de renascimento de cada um para si mesmo e para o mundo através do grupo. Recria o sujeito não pelo isolamento proporcionado pela culpa ou pela vergonha dos seus atos ou aspecto, mas por torná-lo autônomo através do enraizar-se na coletividade Delta. De onde ganha criticidade da problemática que o isolava e adquire tolerância e compreensão de sua vida e das mudanças que quer realizar consigo próprio e junto aos outros, Deltas ou aqueles ainda não são, mas possíveis de virem a se tornar.

O apelidar entre os Deltas, deste modo, parece possibilitar um caminho para a autonomia de cada membro, pelo uso da palavra-síntese da vida passada, anterior ao grupo, e do que é e quer cada vez mais se aprimorar na sua vida presente e futura. Parece funcionar, assim, como uma espécie de metalinguagem comunicativa (Magalhães 1974) que estipula fronteiras e formas de aprimoramento e ultrapassagem para um tipo de construção permanente de cada um e do grupo como um todo, enquanto mensagem ou anunciação de uma vida afirmativa e adequada ao espírito Delta, assumido e advogado para si e para os demais, enquanto vida comum.

A nominação entre os Deltas parece assim ser a parte final de um longo ritual de iniciação. Os apelidos funcionam como uma espécie de batismo que inaugura e enfatiza a entrada de um novo membro no mundo Delta. De onde, coletivamente, cada novo membro se veste com o passado que o afligia para melhor aceitá-lo, compreendê-lo e modificá-lo a partir de então.

O viver com a síntese do passado pessoal, no novo nome adquirido na passagem promovida pelo ato ritualístico de nominação, força cada membro a nunca esquecer o que foi, e a usar o passado como um vigor de enfrentamento do mundo interno e externo ao Delta. Como um sinônimo vivo na carne, como uma agonia que conduz na sua anuência de sofrimento a possibilidade de libertação, sempre a partir de um lugar de 
origem, de um lugar de referenciação, que tornou e torna dia após dia cada membro em um anunciador, dentro de um processo diariamente renovado de imersão ao grupo Delta ${ }^{9}$.

$\mathrm{O}$ ato de apelidar, no ritual de nominação entre os Deltas, portando, permite a verificação do outro através da própria experiência, como uma espécie de tempo contínuo que integra passado, presente e futuro, através da apropriação do passado enquanto ruptura e de estar no mundo agora e no amanhã. $O$ estar no mundo, a partir do batismo Delta, inaugura também um espaço de compreensão do eu enquanto nós. $E$ do nós, coletividade Delta, através do aprimoramento permanente de cada um e da ampliação do espaço e do espírito do grupo aos demais.

$O$ ato de apelidar trama, ou assim o parece, uma experiência espaço-temporal do grupo e, simultaneamente, estabelece um processo ininterrupto de constante reinauguração enquanto sistema simbólico de sociabilidade e pertença em cada um dos membros nele atuante.

A cada "rodada de conversa" o grupo, ao fazer o repasse de cada um na nominação das trajetórias anteriores à pertença ao Delta, vai como que descobrindo o nome a ser dado a cada novo membro e possibilitando a imersão dos novos e a solidificação dos laços dos antigos membros no grupo. Uma contínua reinauguração do coletivo e de cada um dos seus membros parece ser então elaborada através das "rodadas de conversa", que objetificam o que aqui está se chamando de ritual de batismo de novos membros e da imersão renovada dos antigos, consubstanciando e solidificando pela cristalização ${ }^{10}$ revigorada do espírito de grupo o próprio Delta como movimento organizativo.

Cada batismo é, igualmente, recebido com festa (gargalhadas, brincadeiras, troca de afagos, gestos, afetos) pelos integrantes que também, em certo sentido, renovam os votos para com o grupo no exercício da autocrítica que situa cada um no momento anterior a sua entrada, revivendo o sofrimento do passado e a nova ordem que se abria com o advento da palavra através do apelido dado ou atribuído, mas em todo caso aceito e objeto de remontagem afirmativa de cada vida individual presente e futura.

A cada novo batismo, a cada novo ritual de nominação, a cada "rodada de conversa", todos os membros ouvem, vêem e reafirmam os seus novos nomes e a descoberta de um sempre novo espírito grupal que os une mais, através da inserção de um outro membro - o que os faz reviver a onomástica enquanto simbologia que funda e reinventa a cada novo membro a tradição Delta. Em cada ritual de nominação, assim, há o esforço de relacionar os novos membros com a comunidade atual. Esta última os recepcionando com a história de cada um dos que dela já faziam parte e os levando a aderir pela imersão a partir da história de cada iniciante, afirmando o caráter coletivo da entrada no grupo como identidade de passados e afirmação de um novo renascimento a partir do batismo. 
Uma relação profunda de pertença entre os indivíduos parece ser instituída, assim, através da atribuição e assunção de seus novos nomes, como uma espécie de metáfora para referir-se ao ser de cada um por inteiro através do apelido no grupo. Apelido que sintetiza o tempo através da apropriação do passado no nome conferido e assumido, e refunda o espaço como sistema simbólico que remete ao âmago de cada um, consubstanciando as pessoas na relação de cada um com o 'nós' e do 'nós' em cada um.

\section{ONOMÁSTICA, APROPRIAÇÃO DO PASSADO E CONTROLE SOCIAL}

O apelido, ao assumir uma espécie de sinal esculpido de individualidade, como uma tatuagem reveladora do que cada um foi antes da entrada no Delta e modeladora das formas de aceitabilidade no grupo, age, de um lado, como uma espécie de marco distintivo e de reconhecimento individual de cada membro no grupo. De outro lado, porém, parece também atuar como um ponto de flexão sobre a disciplina imposta por cada um a si mesmo e controlada por todos os demais membros, de forma a não decair e superar sempre e cada dia mais os limites que inauguram o novo ser gerado a partir do batismo ou processo de imersão na comunidade Delta.

A consciência de si e a tolerância para com o que se foi, registrada como uma marca na onomástica do grupo, se leva à criação de um novo ser no e para o mundo, implica também a busca, de cada membro e do conjunto comunitário, de superação dos limites individuais através da autocrítica renovada de cada história particular e da objetificação da melhoria alcançada e do quanto deve ainda ser conseguido para tornar-se plenamente um Delta.

Em um artigo anterior sobre o grupo (Koury 2002) se discutiu a questão da reciprocidade entre os membros como uma espécie de expectativa individual de ser digno e de descobrirem-se merecedores e mantenedores de apreço e consideração, enquanto ato ou conjunto de ações confiáveis na coletividade, isto é, como um tipo de compromisso moral. Faz parte da reciprocidade Delta, assim, a fidelidade aos princípios morais do grupo e a lealdade com e nos outros, e a revelação de que é o grupo que permite e garante a visibilidade das individualidades nele imersas. Na perspectiva Delta, portanto, só há indivíduo no grupo e sem o grupo não há possibilidade de individualidade.

Um constante e continuado exame da organização sobre o comportamento de cada um no interior e fora da comunidade, neste sentido, faz parte da performance Delta. Nesta permanente avaliação os compromissos baseados na fidelidade e na fiabilidade são checados e as advertências dispostas de forma 
imediata aos indivíduos em prova. Através de instrumentos disciplinares controlam-se as atitudes individuais e movimenta-se um contínuo de afirmação do compromisso Delta por cada membro e uma vigilância de todos sobre a manutenção do contrato social de cada um. Na expressão da existência do corpo Delta acima de cada membro prevêem-se demonstrações de invisibilidade do sujeito em teste ou da demonstração da sua não existência e importância para o grupo como totalidade.

As "rodadas de conversa", deste modo, são imprescindíveis para este demonstrativo permanente de reciprocidade baseado na lealdade e na confiabilidade. Os apelidos, da mesma forma, são instrumentos eficazes de medição do esforço particular de cada membro para sua atuação no conjunto grupal. Ambos são sentidos como um duplo e simultâneo desafio: à compreensão dos laços de intimidade e de similaridade entre os membros, e como fundamento de balizas da individualidade de cada um, pela aspiração de pertencer.

“Toda vez que tem uma rodada eu me sinto, ao mesmo tempo, constrangido e exuberante. Não sei bem por quê. Eu acho que é por causa de eu ter que relatar tudo, tudinho mesmo o que eu fui antes de ser um Delta, falar de como me sentia, de como me sinto, e falar do que eu estou fazendo para me melhorar e levar com decência o nome do grupo onde quer que eu esteja. Falar do que eu fui até que é fácil, pois em certa parte é reviver na fala o apelido que uso como minha identidade e identificação: eu sou o Língua Ruim, como o senhor sabe. Falar de como me tornei e como sou outra pessoa depois que entrei na comunidade, também é legal. Meus olhos sempre brilham, eu me empolgo, me coloco mesmo com toda exuberância como falo no depois da minha entrada. O mesmo acontecendo quando vejo que os outros Deltas também passaram poucas e boas e hoje são muito melhores do que eu. Eu vibro...".

"Eu fico constrangido, porém, toda vez que tenho que omitir que eu ainda sou pêgo com freqüência querendo falar mal, fuxicar, me envolver no que não devo... fico me cagando pra que os outros não descubram e me cobrem, me dêem um caldo ou ponham no gelo e me façam sair do grupo. Aí sou todo apertado, falando aqui, saltando ali, revelando alguns sufocos, mas dizendo da minha luta para não me deixar cair, e coisa e tal... Mas no geral eu vibro e me asseguro de que só o Delta me deu aquilo que eu sempre busquei, um grupo de apoio, um grupo de irmãos, um grupo que me faz cada vez mais buscar ser eu mesmo ao me superar a cada novo ganho... só que as dificuldades são grandes e eu às vezes me sinto pra lá de solitário, não ousando confiar em ninguém os meus dramas mais íntimos, com medo de ser mal entendido e me dar mal e voltar pra vida que eu levava antes, de rejeitado e sem amigos e, ao mesmo tempo, me sentindo culpado por agir assim..."11.

Os apelidos, ao serem repassados enquanto narrativas de curvas de vidas de cada membro nas "rodadas de conversa", lembram a todo o momento, de um lado, o que se foi e que se quer reparar e superar, ao 
próprio sujeito vestido e representado no grupo através do seu nome. Demonstram, também, de outro lado, uma lógica de igualdade de todos os membros via vestimenta da aflição e ansiedade, como uma espécie de carga simbólica da necessidade de superação e de não se recair em erros do passado, o que parece tornar cada membro um ser diferente pela subsunção ao todo. $E$, simultaneamente à vestimenta desta aflição e ansiedade, uma sobreveste de medo. Medo de revelar as fraquezas e recaídas ao ser que já foi e de ser mal entendido pelos demais membros do grupo, o que os torna, freqüentemente, em indivíduos discretos e de emoções ambivalentes, como parece revelar o depoimento do Língua Ruim acima, reforçando o caráter moral do grupo sobre cada membro individual.

A acepção conferida pela atitude moral do grupo, se consente e proporciona garantia a cada membro individual e à prática grupal pela disposição da lealdade, parece induzir uma censura inflexível a cada membro singular e a todos os membros para as ações proferidas solitariamente, ou em conjunto, por cada um deles. A narrativa do Língua Ruim sugere plainar entre os Deltas, indivíduos ou grupo, uma ininterrupta intimidação, gerando atitudes ambíguas, sobre como se comportar, como se portar, o que expor e o que silenciar.

Parece, deste modo, que atitudes, gestos, ações, confissões, declarações ou reações são firmemente avaliadas no grupo, sem carecer de um dispositivo especial para que isso ocorra. A segurança de fidelidade ao grupo e de cada Delta consigo próprio parece passar por um processo de extrema vigilância de um sobre os outros.

Os membros colocados sob observação mais intensa são, por seu turno, sujeitos a dispositivos disciplinares como o caldo e o gelo. O indivíduo em condição de gelo passa por uma situação de estranha invisibilidade, é ignorado pelos demais como se não existisse ninguém ao redor. Não há agressão verbal nem física, apenas uma expressão de sentimento de inexistência do outro.

O caldo como método disciplinar é uma tentativa de sufocar social, de fazer o indivíduo nele incluso sentir-se perdido, solitário e sem apoio, sequer de um olhar. As buscas de aproximação de um indivíduo em caldo são tentativas vãs, pois para os demais membros do grupo é como se não houvesse ninguém se aproximando: os círculos ou pequenos grupos de conversa prosseguem ou se dispersam, e lidam com o membro suspeito como se ele não existisse. Acirrado pela suspeita ou rompimento das convenções junto ao todo, o processo de individuação do membro em situação de caldo ou gelo em relação ao grupo é ritualizado.

Processo ritual onde se provoca a invisibilidade do membro em julgamento para com o grupo. Ritual onde se remonta a idéia de coesão interna através da separação do outro, com a invalidação dos vínculos societários para com ele. A invisibilidade e inexistência do outro é corroborada pela demonstração da visibilidade e corporeidade do grupo, de sua coesão interna movidas pelas regras de confiança e irmandade. 
Este ato ritualístico tem por objetivo evidenciar para o próprio grupo a noção de segurança como o componente imperativo ao custeamento do social. Os dispositivos disciplinares, conceito empregado aqui próximo ao uso atribuído por Foucault (1977), existem então no grupo para os casos comprovados de desconfiança ou evidência de faltas graves. Dispositivos que podem chegar a induzir os membros a comportamentos extremados de imposição de isolamento e sofrimento a quem o recebe. A sensação de invisibilidade posta sobre o suspeito diz respeito, assim, às introjeções individuais sobre como ser um Delta, onde as ações de cada um são movidas pela presença constante de um forte sentimento de vergonha ${ }^{12}$ de expressão sobre as incoerências vivenciadas ou experienciadas por cada membro individual, e do medo de ser acometido por atos que possam ser considerados como não coerentes ao que se espera de um Delta.

As "rodadas de conversa", deste modo, se equivalem a um mergulho ao âmago do grupo e a cada um dos Deltas, através da peculiar onomástica presente em forma de atribuição de apelidos aos novos e como rememoração constante para todos os membros do que cada um foi e de como cada qual ressurgiu na vivência no grupo, reforçando a moral e a cultura igualitária presente na simbólica grupal, diz respeito, também, a toda uma construção interna das emoções de cada sujeito no grupo pela coletividade (Mauss 1980). A questão do poder surge no sistema de nominação através da forte discrição que cada membro tem de se revelar ao outro, embora advoguem o contrário em uma primeira conversa e a revelação do si seja a marca de igualitarismo na ideologia Delta.

O medo de ser pêgo em flagrante delito, mesmo através da palavra ou pensamento, e não necessariamente da ação, faz com que cada membro se recolha a si mesmo e omita referências que possam ser mal interpretadas, ou nas palavras de Malcheirosa ${ }^{13}$, "meço constantemente o que eu digo e presto atenção a tudo o que todos os demais dizem. É uma forma de ficar atenta ao bom convívio entre nós todos e à boa atuação de tudo o que o grupo deu a nós e que a gente tem que conservar acima de qualquer coisa. A única forma de ser igual é ficando atenta ao que se passa nas conversas, nas coisas que todos fazem. E tendo o cuidado de não deixar revelar as tentações que passam pelas cabeças, a não ser com muito cuidado, para que possam ser gozadas e não servirem como desgraça de quem as disse ou de quem as ouviu dizer."

Uma má interpretação poderá vir acompanhada de várias atribulações para a pessoa nela envolvida. Desde as etapas de evitação até a possível expulsão do grupo são imaginadas por cada membro com uma espécie de grande receio de ser o que está na berlinda. Estar na berlinda para os Deltas é estar sob suspeição, sob os olhares de toda a coletividade. É anterior ao ato de evitação pública e implica para quem nela é colocado sentir-se em constante vigilância, não só de olhares, mas de perguntas, de "jogar verde para colher maduro", como informa Mãozinha ${ }^{14}$ : "Quando o fulano sente que qualquer palavra que disser ou gesto que 
fizer pode ser fatal pra ele, e ele fica sem saber onde pôr os pés, as mãos, sem saber onde colocar nada, só apavorando cada vez mais, só apavorado, até que pergunta o que tá havendo, e aí começa a coisa do fazer que não tá vendo, que não tá acontecendo, que até o sujeito não existe".

“Começa o gelo brabo, e ele fica sem referências, e tem gente que conheço que quis até morrer... Em muitos casos, depois que há uma averiguação e se vê que o cara não tava mal intencionado e tal, dá-se um jeito de recompô-lo, mostrando a ele que o caminho aqui é de ser igual, tudo todo mundo sabendo, até os fraquejos têm que ser ditos para não haver interpretação errada. Mas, mesmo assim, de volta, o sujeito sente que o jeito de continuar é dizendo tudo e nada ao mesmo tempo... e aí a vida continua e a gente volta à irmandade de sempre. E o erro que se cometeu é encarado como erro e como passado que não se quer mais voltar".

Em outro trecho da longa entrevista, Mãozinha informa: "Eu assisti uns irmãos que depois de uma bolada toda de um negócio que chegou a beirar a expulsão do grupo que, quando tudo acabou, em uma rodada de conversa propôs trocar de apelido, para um condizente com o fato que fez ele ser quase colocado para fora, e o pessoal topou ele trocar de apelido, mas achou melhor, e ele também, ser chamado de Melão, pela melada que ele fez ou quase ia fazendo... Eu vou apresentar ele pro senhor pra ele contar essa história dele. Acho que o senhor vai gostar de ouvir"15".

Nas "rodadas de conversa", deste modo, não apenas é rememorado o que se foi para os já integrados ou se dá o batismo dos novos membros, mas também a imersão dos antigos que se sentiram em falta grave, com a busca de um novo apelido que assegure no código onomástico Delta um outro ressurgimento para o mundo interior grupal e fortaleça a essência individual do membro reerguido. Embora não seja uma prática comum, o caso de Melão não deixa de ser exemplar para se pensar a configuração simbólica dos apelidos enquanto renascimento para a vida Delta, enquanto ação cultural e eficácia moral do coletivo sobre cada um dos membros e, melhor, de cada um dos membros enquanto rememoração constante do seu ressurgir, para a consolidação e solidificação grupal. Ambos agindo no sentido de uma permanência atemporal do grupo sobre as temporalidades individuais: o grupo permanece, sempre parece ter razão, já que oferece vida e visão de mundo e sem ele nenhum membro é nada, pois que sujeito a erros e deslizes motivados pela história privada de cada um.

Quanto menos privadas as emoções experimentadas forem por cada um dos membros, mais o coletivo parece ter a possibilidade de uma ação eficaz sobre cada um, admoestando e resolvendo pendências criadas pela singularidade de cada curva de vida, e fazendo cada membro, nele respaldado, ser diferente no mundo para fora, sendo igual internamente e sujeito de individualização no grupo pelo esforço perseguido da perfeição. 
O sistema de nominação, através dos apelidos, assim, é fundamental para a existência e solidificação do grupo Delta e para a compreensão social de sua lógica interna de interação e reciprocidade.

A onomástica age, através das "rodadas de conversa" onde o ritual de nominação é realizado, pelo incentivo constante ao mea culpa dos seus membros. A partir da atribuição dos apelidos e do sistema de revisitação constante do que se foi nas "rodadas de conversa", o ato de rememoração individual pode ser compreendido como uma forma de controle grupal e, simultaneamente, uma forma de emergência de um novo ser Delta, no e para o mundo. É, sobretudo, a garantia da memória simbólica do grupo sobre cada um dos membros individualizados e sobre todos em conjunto.

\section{CONCLUSÃO}

Este artigo discutiu o significado da atribuição de apelidos em um grupo de jovens da cidade de João Pessoa, Paraíba, partindo da hipótese de que o seu uso ostenta uma forma de registro de individualidade e de aceitabilidade no grupo. O cognome dado parece ser associado a uma marca pessoal distintiva de reconhecimento individual e de medição do esforço constante para aprimoramento pessoal no grupo, o que possibilita analiticamente a compreensão da relação dos apelidos à situação de pertença e do controle social entre os Deltas.

Em um primeiro momento, foi necessário estabelecer uma distinção metodológica das noções de apelido e de alcunha, entendendo o primeiro como de conteúdo mais social que o segundo, e nele atestando um sentimento de pertença, enquanto interpessoalidade, que parece colocar o sujeito no mundo em sua relação com o outro, ou com o objeto da sua relação. O que parece torná-lo pessoa pela atribuição e uso de um apelido. O sistema de nominação Delta através dos apelidos, assim, parece agir como uma metalinguagem, estimulando o sentimento de pertença de cada membro ao grupo. Provoca, em cada membro, uma atitude de autocompreensão e respectivamente de compreensão e inserção no mundo Delta e fora dele. O apelido, assim, funciona como um desafio pessoal para o reconhecimento da memória de antes da entrada no grupo, e significa aquilo que não mais quer ser.

O apelidar entre os Deltas abre caminho para autonomia de cada membro, pelo uso da palavra síntese da vida passada, anterior ao grupo, e do que é e quer cada vez mais se aprimorar na vida presente e futura. A experiência de viver com a síntese do passado pessoal, no novo nome adquirido através do apelido, força cada membro a nunca esquecer o que foi, e a usar o passado como um vigor de enfrentamento do mundo 
interno e externo ao Delta. O que parece instituir uma relação profunda de pertença entre os indivíduos através da atribuição e assunção de seus novos nomes, como uma simbólica que faz referência ao ser de cada um por inteiro através do apelido auferido. O que provoca uma simultaneidade de ações que atentam para uma síntese do tempo através da apropriação do passado no nome assumido, e refundam o espaço grupal como sistema simbólico no âmago de cada um, consubstanciando as pessoas na relação das trocas realizadas no interior grupal ou por meio dele.

O apelido age como uma marca na onomástica do grupo e, se leva à criação de um novo ser no e para o mundo, implica também a busca de superação dos limites individuais e da objetificação da melhoria alcançada e do quanto deve ser perseguido para o vir a ser plenamente um Delta. O que parece reforçar a perspectiva Delta de só haver indivíduo no grupo e de não existir possibilidade de individualidade fora da coletividade.

De onde surge a questão do poder, no sistema de nominação Delta, a ação cultural e a eficácia moral do coletivo sobre cada um dos membros como uma garantia da memória simbólica do grupo. A onomástica agindo, através do incentivo constante ao mea culpa, para a transformação do ato de rememoração individual em uma forma de controle grupal e, simultaneamente, na possibilidade de emergência de um novo ser Delta, no e para o mundo. De onde se pode compreender, enfim, para conclusão, que o sistema de nominação Delta e a prática de rememoração constante do que se foi, através dos apelidos, agem na direção de um renascimento individual, e ao assim o fazerem recriam o grupo pela permanência e solidificação de sua presença no interior de cada sujeito e entre os seus membros em relação. 


\section{NOTAS}

1 Delta é um nome fictício do grupo de jovens estudado. Não se usa, neste artigo, o nome com que eles se auto-designam para evitar possíveis embaraços para com o grupo ou seus membros. É importante, porém, evidenciar a existência de um nome para o grupo pelos que dele fazem parte. O reconhecimento através do nome, ou da denominação de si próprios como membro, parece construir e ampliar o sentimento de pertença ao grupo. Pertencer ou sentir-se pertencendo é ser um Delta. O trabalho de campo com os Deltas faz parte de uma pesquisa maior vinculada ao GREM - Grupo de Pesquisa em Antropologia e Sociologia da Emoção da Universidade Federal da Paraíba, intitulada "Medos Corriqueiros: a construção social da semelhança e da dessemelhança entre os habitantes urbanos das cidades brasileiras na contemporaneidade", iniciada em janeiro de 2002. Nesta pesquisa maior se busca compreender a construção social do medo como parte integrante do jogo formador de sociabilidades e conformações sociais através da ação ordinária e cotidiana dos atores urbanos nas capitais dos estados brasileiros na contemporaneidade. Um primeiro artigo sobre o grupo foi publicado anteriormente na RBSE - Revista Brasileira de Sociologia da Emoção (Koury 2002).

2 O grupo Delta e seus membros empregam muito as expressões "novo ser" e "novo ser no e para o mundo" para designar as mudanças ocorridas a um indivíduo no momento de adesão ao movimento. Este trabalho usará estas expressões também com este sentido e, a não ser quando no interior de uma narrativa de um entrevistado, o seu uso será parte integrante do texto e não se usará aspas.

3 Por uma questão de espaço, não se fará neste artigo uma revisão da bibliografia sobre o tema clássico dos sistemas de nominação na antropologia. Recomenda-se, porém, para um aprofundamento da temática a leitura de Lévi-Strauss (1970), Geertz (1978), Evans-Pritchard (1940), Colson (1962), Lopes da Silva (1986), Gonçalves (1993) e Oliveira (1998), entre outros. Ver, também, para o caso do uso de cognomes na Internet o ensaio de Maldonado (2003) e o verbete nicknames da enciclopédia Wikipidia (2003).

4 O socialmente, aqui empregado, diz respeito à sociedade mais ampla, na qual o indivíduo específico e o grupo Delta, como um todo, estão inseridos.

5 George Mead (1934), um dos fundadores da Escola de Chicago, distingue três noções que configuram o ator social enquanto figura psicológica e social em um processo de interação. Estas três noções são a do eu, a do a mim e a do mim. O eu, representando mais a configuração do sujeito individual, e o a mim a composição do objeto da ação deste sujeito individual. A interpessoalidade constante na noção de mim, diferente das duas primeiras, deste modo, representa a base que alicerça o sujeito no mundo.

6 Entrevista concedida em 31 de janeiro de 2003.

7 Em 23 de junho de 2002.

8 Em 15 de dezembro de 2002.

9 Ver, para uma analogia com a idéia de sofrimento e de libertação no cristianismo, Kristeva (1988:163 - 222) e Carse (1987: 245 280).

10 Cristalização no sentido ambivalente da palavra, de solidificação de cristais, e de encantamento, no brilho esfuziante que parece provocar em que o observa, no sentido dado por Stendhal (1993).

11 Entrevista realizada em 21 de fevereiro de 2003, após vários encontros e conversas informais com o informante. Rapaz de 23 anos, com o segundo grau completo há dois anos e que se prepara para iniciar o curso de Direito na Universidade Federal da Paraíba (UFPB). Trabalha com o pai em um escritório de representação comercial no centro de João Pessoa.

12 Para um aprofundamento sobre a emoção de vergonha ver, entre outros, Elias (1990 e 1993), Harkot-de-la-Taille (1999) e Koury (2003).

13 O apelido de Malcheirosa vem das constantes humilhações de que se diz vítima antes de entrar no Delta por viver em uma rua de palafitas na beira do rio Sanhauá, em João Pessoa, sempre sujeita a enchentes, por causa da alta da maré, e pelo constante cheiro de lama do leito do rio quando da maré baixa. E por querer esconder o fato de morar em um lugar tão pobre para todos os colegas do colégio onde estudou até o primeiro ano do segundo grau. Malcheirosa tem 20 anos, tem dois filhos de pais diferentes e trabalha 
em uma lanchonete do centro da cidade de João Pessoa. Atualmente mora em duas ruas acima da rua onde morava, em uma "casa pobre, mas decente. Limpinha e cheirosa". Entrevista realizada em 03 de março de 2003.

14 Entrevista concedida em 22 de janeiro de 2003. Mãozinha é um rapaz de 18 anos com um defeito de nascimento no braço esquerdo que "me incomodava muito e me fazia sentir rejeitado por todos, até que eu entrei no Delta". Mora com a família, está terminando o segundo grau em um colégio estadual do centro da cidade de João Pessoa.

15 Até o presente momento não foi possível entrevistar Melão, embora o pesquisador já tenha sido apresentado a ele e ele tenha concordado em conversar mais formalmente. Mas o fato contado por Mãozinha foi assegurado ser verdadeiro por vários membros do grupo entrevistados, ou em rodas de conversa informal com o pesquisador. 


\section{REFERÊNCIAS BIBLIOGRÁFICAS}

CARSE, James P. 1987. Muerte y Existencia: una historia conceptual de la mortalidad humana. México: Fondo de Cultura Económica.

COLSON, Elizabeth. 1962. The Plateau Tonga of Northern Rhodesia: social and religious studies. Manchester: Manchester University Press.

ELIAS, Norbert. 1990. O Processo Civilizador, vol. 1. Rio de Janeiro: Zahar.

ELIAS, Norbert. 1993. O Processo Civilizador, vol. 2. Rio de Janeiro: Zahar.

EVANS-PRITCHARD, E. E. 1969. The Nuer: a description of the Modes of livelihood and political institutions of a nilotic people. New York and Oxford: Oxford University Press.

FOUCAULT, Michel. 1977. Vigiar e Punir. Petrópolis: Vozes.

GEERTZ, Clifford. 1978. "Pessoa, Tempo e Conduta em Bali”. In A interpretação das Culturas. Rio de Janeiro: Zahar.

GOFFMANN, Erving. 1988. Estigma. Notas sobre a manipulação da identidade deteriorada. 4ª edição. Rio de Janeiro: Guanabara.

GONÇALVES, Marco Antonio. 1993. O Significado do Nome: cosmologia e nominação entre os Pirahã. Rio de Janeiro: Sette Letras.

HARKOT-DE-LA-TAILLE, Elizabeth. 1999. Ensaio Semiótico sobre a Vergonha. São Paulo: Humanitas.

KOURY, Mauro Guilherme Pinheiro. 2001. “Enraizamento, Pertença e Ação Cultural”. Cronos 2(1):131-37.

. 2002. “Confiança e Sociabilidade. Uma análise aproximativa da relação entre medo e pertença”. Revista Brasileira de Sociologia da Emoção 1(2):171- 205. Disponível em_http://www.rbse.rg3.net.

2003. Sociologia da Emoção. Um estudo do Brasil urbano sob a ótica do luto. Petrópolis: Vozes.

KRISTEVA, Julia. 1988. Histórias de Amor. Rio de Janeiro: Paz e Terra.

LÉVI-STRAUSS, Claude. 1970. O Pensamento Selvagem. São Paulo: Cia. Editora Nacional.

LOPES DA SILVA, Aracy. 1986. Nomes e Amigos: da prática Xavante a uma reflexão sobre os Jê. São Paulo: FFLCH/USP. MACHADO, José Pedro. 2001. Dicionário Etimológico da Língua Portuguesa. São Paulo: Arsenal.

MAGALHAES Jr, Ricardo. 1974. Como Você se Chama? Estudo sócio-psicológico de prenomes e cognomes. Rio de Janeiro: Editora Documentário.

MALDONADO, Simone Carneiro. 2003. "A Chama Dourada: sociabilidade e religiosidade na internet". BOCC-Biblioteca On-Line de Ciências da Comunicação. http://www.bocc.ubi.pt (texto consultado em 10/03/2003).

MAUSS, Marcel. 1974 [1934]. “As Técnicas Corporais”. In Sociologia e Antropologia, vol. II São Paulo: EPU/EDUSP. . 1974 [1925]. “Ensaio sobre a Dádiva. Forma e razão da troca nas sociedades arcaicas”. In Sociologia e Antropologia, v. II. São Paulo: EPU/EDUSP.

. 1980. “A Expressão Obrigatória dos Sentimentos". In Sérvulo Augusto Figueira (org.) Psicanálise e Ciências Sociais.

Rio de Janeiro: Francisco Alves. 
MEAD, George. 1934. Mind, Self and Society. Chicago: University of Chicago Press.

OLIVEIRA, João Pacheco de. 1998. “Uma etnologia dos 'índios misturados'? Situação colonial, territorialização e fluxos culturais". Mana 4(1):47-77.

STENDHAL. 1993. Do Amor. São Paulo: Martins Fontes.

WIKIPIDIA Free Encyclopedia. 2003. http://www.wikipedia.org/wiki/wikipedia (verbetes consultados em 25/02/2003). 


\author{
Sistema de Nominação, Pertença, Medos e Controle Social. $\mathrm{O}$ uso dos apelidos entre um grupo de jovens da \\ cidade de João Pessoa, Paraíba. \\ RESUMO
}

Este artigo discute o uso dos apelidos entre um grupo de jovens da cidade de João Pessoa, Paraíba, aqui denominado Delta. $\mathrm{O}$ apelido age como uma marca e se leva à criação de um novo ser no e para o mundo, implica também a busca de superação dos limites individuais e a objetificação da "melhoria" alcançada e do esforço para a plena aceitação no grupo. Isto reforça a perspectiva de só haver indivíduo no grupo e não existir possibilidade de individualidade fora da coletividade, fazendo emergir a questão do poder no sistema de nominação do grupo. A onomástica age, através do incentivo constante ao mea culpa, na transformação do ato de rememoração individual em uma forma de controle grupal e, simultaneamente, na possibilidade de emergência de um novo ser. $\mathrm{O}$ sistema de nominação e a prática de rememoração do que se foi através dos apelidos parecem agir, enfim, na direção de um renascimento individual, e ao assim o fazerem recriam o grupo pela permanência e solidificação de sua presença no interior de cada sujeito e entre os membros em relação.

PALAVRAS CHAVE: Sistema de Nominação; Pertença; Medos; Controle Social; Sociabilidade.

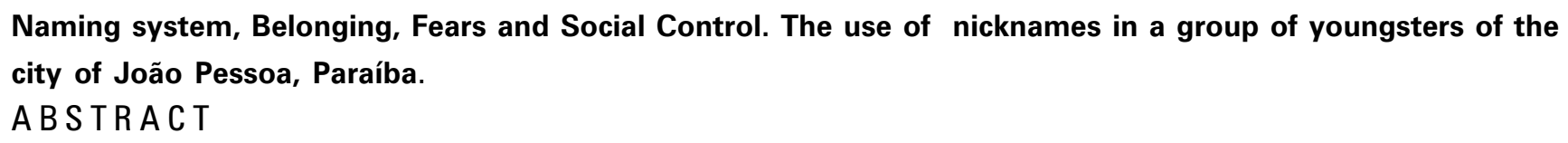

This article discusses the use of nicknames in a group of youths of the city of João Pessoa, Paraíba, Brazil, mentioned here as Delta. The nickname acts as a marker and leads to the creation of a new being. It also implies a search for overcoming individual limits and objectifies personal improvements reached and the effort for the full acceptance in the group. It reinforces the perspective of there existing individuality only within a group and not without a collective, making it to emerge the subject of power in the group's system of nomination. Through the constant incentive to the mea culpa, these onomastic practices, transform the act of individual remembrance in a form of collective control and, simultaneously, in the possibility of the emergence of a new being. The nomination system and the remembering practice through the nicknames seem to act, finally, in the direction of an individual renaissance, and in so doing recreate the group through permanence and structuring of its presence inside each subject and among the members in relationship.

KEY WORDS: Naming System, Belonging; Fears, Social Control, Sociability 